\title{
The effect of storage at ambient temperature on the feline fecal microbiota
}

\author{
Moran Tal', Adronie Verbrugghe ${ }^{1 *}$, Diego E. Gomez ${ }^{2,3}$, Charlotte Chau $^{1}$ and J. Scott Weese ${ }^{2}$
}

\begin{abstract}
Background: Feline fecal microbiota analyses can potentially be impacted by a variety of factors such as sample preparation, sequencing method and bioinformatics analyses. Another potential influence is changes in the microbiota from storage of samples prior to processing. This study examined the effect of ambient temperature exposure on the feline fecal microbiota composition.

Fecal samples were collected from 12 healthy cats, within 15 min after defecation. Samples were aliquoted and the first aliquot was frozen at $-80^{\circ} \mathrm{C}$ within 1 hour of defecation. Remaining aliquots were maintained at ambient temperature $\left(20\right.$ to $23^{\circ} \mathrm{C}$ ) and frozen at $-80^{\circ} \mathrm{C}$ at $6,12,24,36,48,72$ and $96 \mathrm{~h}$ after collection. DNA was extracted from all aliquots, and polymerase chain reaction (PCR). The PCR products were sequenced with next-generation sequencing (Illumina MiSeq).

Results: No significant differences were observed in alpha and beta biodiversity indexes, as well as relative abundance of different taxa over time ( $P>0.05$ for all tests between time points). Principal coordinate analyses demonstrated that samples cluster mainly by cat, with no significant differences between time points (AMOVA, $P>0.05$; HOMOVA, $P>0$. 05). Linear discriminant analysis effect size method was performed and failed to detect any enriched taxa, between time points. Random forest algorithm analysis indicated homogeneity across time points.

Conclusions: Although existing evidence from human fecal storage studies is contradictory, a recent study in companion animals agreed with the current study, demonstrating that maintenance of feline fecal samples at ambient temperature for up to 4 days has no effect on the bacterial membership and structure.
\end{abstract}

Keywords: Gastrointestinal, Fecal, Microbiota, Storage, Temperature, Ambient

\section{Background}

The human gastrointestinal (GI) microbial community (the 'microbiota') is extremely complex in composition, and very high in concentration, reaching $10^{12}-10^{14}$ cell/ $\mathrm{g}$ of intestinal content. The microbiota is dominated by bacteria, but also consists of Archaea, viruses, fungi and parasites. The bacterial concentration progresses from the stomach to the colon, with the highest concentration found in the colon [1-4]. Similar numbers are found in dogs and cats, although composition and bacterial species dominance are different from humans $[5,6]$. Increased evidence exists in humans and companion animals for the health implications and clinical importance of the commensal or symbiotic relationship

\footnotetext{
* Correspondence: averbrug@uoguelph.ca

'Department of Clinical Studies, Ontario Veterinary College, University of Guelph, Guelph, ON N1G 2W1, Canada

Full list of author information is available at the end of the article
}

between the intestinal bacteria and their host. The intestinal microbiota plays a crucial role in the development of the host immune system, protection against pathogens, toxins and mutagens and utilization of excess nutrients or nutrients that are unavailable to the host [7]. The microbiota produces short chain fatty acids (SCFAs) that serve as energy sources to the colonocytes, produces vitamins, and aids in mineral absorption and intestinal integrity, along with a myriad of other effects, many of which remain to be properly defined $[5,8,9]$.

Any deviation from the 'normal' microbiota is referred to as intestinal dysbiosis $[5,10]$. In humans, animal models and companion animals, dysbiosis can be associated with a range of disease states, particularly inflammation [11-14]. Alterations of the normal gut microbiota balance $[15,16]$, due to inherent, environmental or immunological factors can be involved in the pathogenesis of intestinal inflammatory diseases [11, 17- 
19], or with other organ-related diseases, such as diabetes mellitus, obesity or asthma [2, 20-22].

In order to characterize the human or animal microbiota, a variety of methods can be used. In the past, the use of bacterial cultivation techniques dominated, but results are limited because of the inability to grow a large percentage of the microbiota using standard culture methods [23, 24]. Recently developed highthroughput techniques, such as Illumina MiSeq, are capable of quick massive parallel sequencing, providing more into-depth understanding of human and companion animal microbiome, and are considered as the preferred analytical method nowadays [25].

Aside to the effects of DNA extraction methods [26] or molecular tools, fecal sampling technique and sample storage conditions can potentially influence phylogenetic identification. The effects of different sampling and storage methods on the fecal bacterial population of healthy and diseased human subjects were examined [27]. Fecal samples were aliquoted within $10 \mathrm{~min}$ of defecation and stored at different temperatures: $-80{ }^{\circ} \mathrm{C}$, at $-20{ }^{\circ} \mathrm{C}$ for a week, at $+4{ }^{\circ} \mathrm{C}$ for $24 \mathrm{~h}$ and at ambient temperature for $24 \mathrm{~h}$. No significant differences were found in the number of operational taxonomic units (OTUs), diversity or richness between the different storage temperatures [27]. This study agreed with the results of previous studies [28], but is in contradiction with others, that reported a mild gradual difference in the fecal bacterial composition when samples were stored at ambient temperature for $24 \mathrm{~h}$ compared to the composition assessed around defecation [29, 30]. Studies evaluating the impact of storage conditions on fecal microbiota in companion animals are scarce. One study in dogs and cats identified limited change in the microbiota from short term $(<2$ week) refrigeration [31]. However, the impact of room temperature storage was not assessed. This is an important aspect to understand for field studies, particularly of species such as cats. Fecal collections for microbiota-related studies in client-owned cats are often challenging, as significant time may pass between defecation, sample collection, and submission for analyses. During this time the sample may be left at room temperature (e.g. overnight in the litter box) before proper storage. The objective of this study was to determine the effect of ambient temperature exposure on the feline fecal microbiota.

\section{Methods}

\section{Sample collection}

Fresh fecal samples were collected from 12 healthy cats located at a cat boarding facility in Guelph, Ontario from June to July 2016. The subjects were determined to be healthy based on information provided to the facility manager by cat owners prior to boarding. Cats were observed closely by facility personnel and fecal samples were collected within 15 min of defecation. Samples were maintained unrefrigerated until arrival at the laboratory. Upon arrival, samples were weighed, ${ }^{1}$ manually homogenized and aliquoted into $200 \mathrm{mg}$ samples. One aliquot was frozen at $-80{ }^{\circ} \mathrm{C}$ within 1 hour of defecation (time point (T) 0 ). The remaining aliquots were kept at ambient temperature $\left(20\right.$ to $\left.23{ }^{\circ} \mathrm{C}\right)$ in a biosafety cabinet. ${ }^{2}$ Aliquots were frozen at $-80{ }^{\circ} \mathrm{C}$ at the following time points: 6,12 , $24,36,48,72,96 \mathrm{~h}$. Downstream processing was then performed on samples that had all undergone the same freezethaw cycle and were processed as a batch.

\section{DNA extraction}

For DNA extraction, a commercial stool extraction $\mathrm{kit}^{3}$ was used according to the manufacturer's instructions. The DNA was collected in $1.5 \mathrm{ml}$ micro-centrifuge tubes, and stored at $-80{ }^{\circ} \mathrm{C}$ until further analysis.

\section{Polymerase chain reaction (PCR)}

The quantity of extracted DNA was assessed using a spectrophotometer, ${ }^{4}$ with readings ranging from 33 to $661 \mathrm{ng} / \mathrm{ml}$. To prepare the 16S rRNA gene amplicons for the Illumina MiSeq system, ${ }^{5}$ all DNA samples were diluted (if needed) to a range of 30 to $100 \mathrm{ng} / \mathrm{ml}$. The V4 region of the 16S rRNA gene was amplified using the forward primer S-D-Bact-0564-a-S-15 (5'-AYTGGGYDTAAAGNG-3'), reverse primer S-D-Bact-0785-b-A-18 (5'-TACNVGGGTATCTAATCC-3'), KAPA HiFi ReadyMix, ${ }^{6}$ and PCR grade water. The PCR cycles were conducted in a thermal cycler. ${ }^{7}$ The purified PCR products were evaluated with $1.5 \%$ agarose gel for gel electrophoresis and DNA was measured using spectrophotometry.

\section{DNA sequencing}

Using an Illumina MiSeq system, the samples were amplified by bridge amplification and sequenced with terminator nucleotides [32]. At least 100,000 reads/sample with sequences of approximately $500 \mathrm{bp}$ in length from $2 \times 250$ paired end reads were obtained [32].

\section{Bioinformatics analyses and statistics}

Mothur v1.36.1 was used for bioinformatics analyses, as well as some of the statistical analyses [33, 34]. Additional statistical analyses were performed using JMP 13.0. ${ }^{8}$ Paired end reads were assembled and filtered to remove sequences greater than 250 base pairs (bp) in length. Sequences with any ambiguous base calls or runs of homopolymers greater than 8 bp were removed. Sequences were aligned to the Silva16S rRNA reference database [35], and those that did not align with the correct region were removed. In addition, chimeras were identified using uchime [36] and removed. Sequences were classified using the RDP classifier (v14) [37], and 
those taxonomic assignments were used to create OTUs using a closed (database-dependent) OTU picking approach. Archeae were removed. Subsampling was performed based on the smallest number of sequences from a sample, to standardize sequence number used for analysis [38].

Alpha-diversity indexes (Shannon diversity [39], Simpson diversity [40] and Chao1 [41]) were calculated to assess evenness, diversity and richness, respectively, and compared between time points using a nonparametric multiple comparisons test (Wilcoxon Each Pair). Relative abundances were calculated for the different taxonomic levels, at each time point. Differences in relative abundance of taxa accounting for $\geq 1 \%$ of sequences within phyla and $\geq 0.1 \%$ within genera were evaluated using nonparametric multiple comparison test (Wilcoxon Each Pair), with $p$-values adjusted using the BenjaminiHochberg correction to control for the false discovery rate [42]. Beta-diversity was assessed, using the classical Jaccard index [43] and Yue \& Clayton index of dissimilarity [44] to examine community membership and population structure, respectively. For visualisation of differences in membership and structure between cats and time points, dendrograms were created, and significance of clustering according to time point was determined using parsimony and unifrac unweighted [45]. Beta-diversity was visualized using principal coordinate analyses (PCoA) and further assessed using analysis of molecular variance (AMOVA) and homogeneity of molecular variance (HOMOVA). Linear discriminatory analysis (LDA) effective size (LefSe) [46] was conducted as well for the identification of genomic features between time points. Random forest algorithm analysis was used to assess the ability to predict group classification, by cat or by time point [47].

\section{Results}

Ninety-three samples were processed from the 12 cats. Three aliquots (two at T96, and one at T72) were not obtained due to small fecal samples size from two cats. A total of 9,118,609 sequences passed all filters, with a median of 93,909 sequences per sample, and a range of 50,315 to 207,127 sequences per sample. A random subsample of 50,315 sequences per sample was used to normalize samples for analysis.

There were no significant differences in evenness, diversity and richness between the different time points (all $P>0.05$ ) (Fig. 1). Median bacterial relative abundance accounting for $\geq 1 \%$ of phyla and $\geq 0.1 \%$ of genera, are presented in Figs. 2 and 3 respectively. No significant differences in relative abundances were noted at any taxonomic level (all adjusted $P>0.05$ ). There was a numerical decrease in Megasphaera (Fig. 3); however, this was not statistically significant (unadjusted $P=0.06$, adjusted $P=0.81$ ).

No differences in community membership (Classical Jaccard index - unifrac $P=0.74$; parsimony $P>0.05$ for all comparisons) or population structure (Yue \& Clayton - unifrac $P=0.83$; parsimony $P>0.05$ for all comparisons) were observed. Clustering by cat, but not time point, was apparent on the dendrograms for both community membership and structure (Fig. 4). Principal coordinate analyses indicated that fecal microbiota mainly clustered by cat, with no significant differences in community membership (Fig. 5a and b) or structure between time points (AMOVA $P>0.05$ and HOMOVA $P>0.05$ for all comparisons).

Linear discriminant analysis (LDA) effect size (LEfSe) analysis failed to identify enriched taxa between time points. Random forest algorithm analysis was performed both to evaluate the ability to differentiate between time points and between cats. When random forest was analysed according to time point, $92 \%$ error rate was established, indicating homogeneity across time points, and a very poor ability to separate samples into their appropriate groups. However, when "cat" was analysed as the group, the error rate was only $15 \%$, indicating a much stronger ability to assign samples to the appropriate cat.

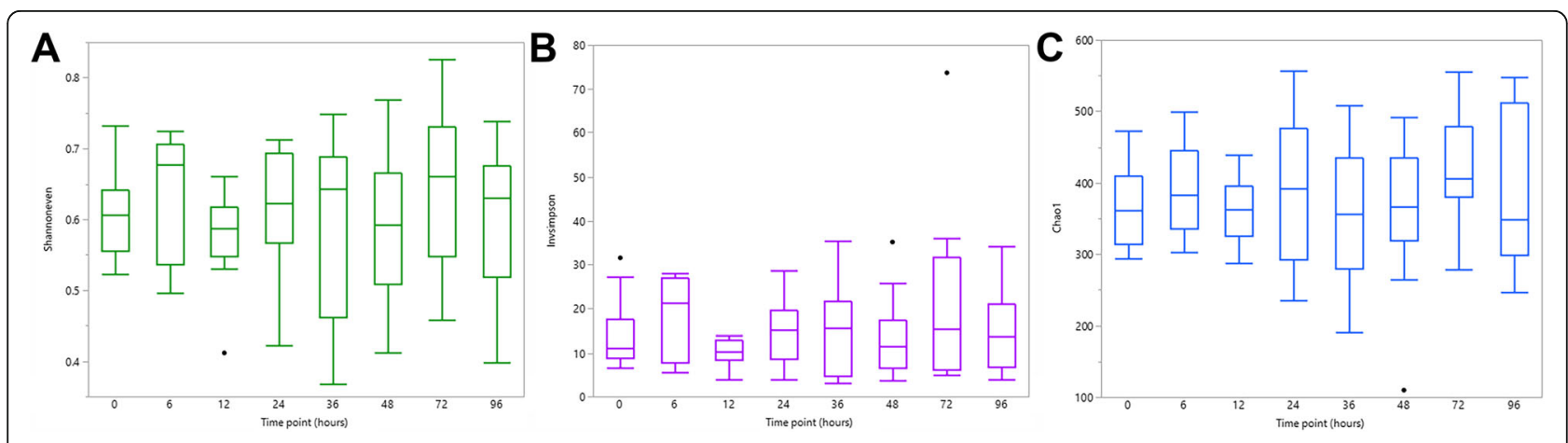

Fig. 1 Comparison of fecal bacterial population evenness (a), diversity (b) and richness (c) in 12 healthy cats between time points 0, 6, 12, 24, 36, 48,72 and $96 \mathrm{~h}$ 


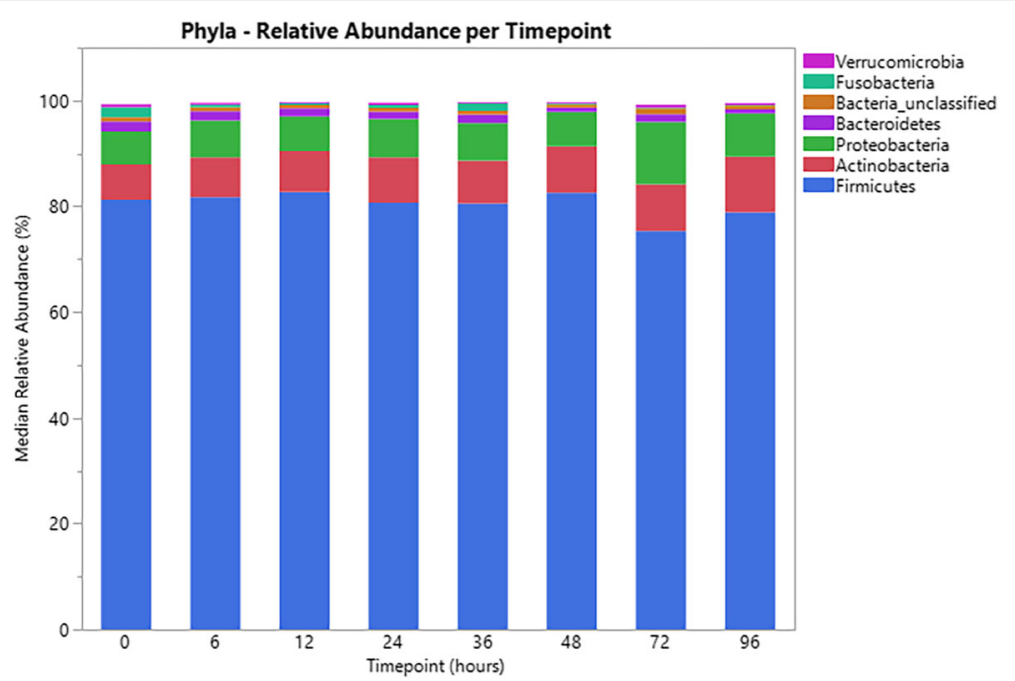

Fig. 2 Comparison of median relative abundances of predominant phyla originating from fecal samples of 12 healthy cats, between time points $0,6,12,24,36,48,72$ and $96 \mathrm{~h}$

\section{Discussion}

The results from the study imply that there are no significant changes in feline fecal microbiota evenness, diversity and richness, as well as community membership and structure over $96 \mathrm{~h}$, while fecal samples are kept at ambient temperature.

Microbiota assessment in feline fecal samples can provide important insight. However, multiple variables can impact the results. It is important to understand potential external influences or biases that might affect the ability to properly define the microbiota and detect true biological differences. The potential impact of sample storage is one potential concern, particularly in studies that involve collection of samples from the community and inherent delays until processing. Understanding the potential influences of sample storage is important for proper design and interpretation of studies.

A variety of ecological indices can be used to assess microbial biodiversity. Despite the use of a range of methods, including assessment of relative abundances and alpha and beta diversity indices, no significant impact of storage on the fecal microbiota was identified. In addition to statistical analyses, clear numerical, nonstatistically significant, differences were evident. While

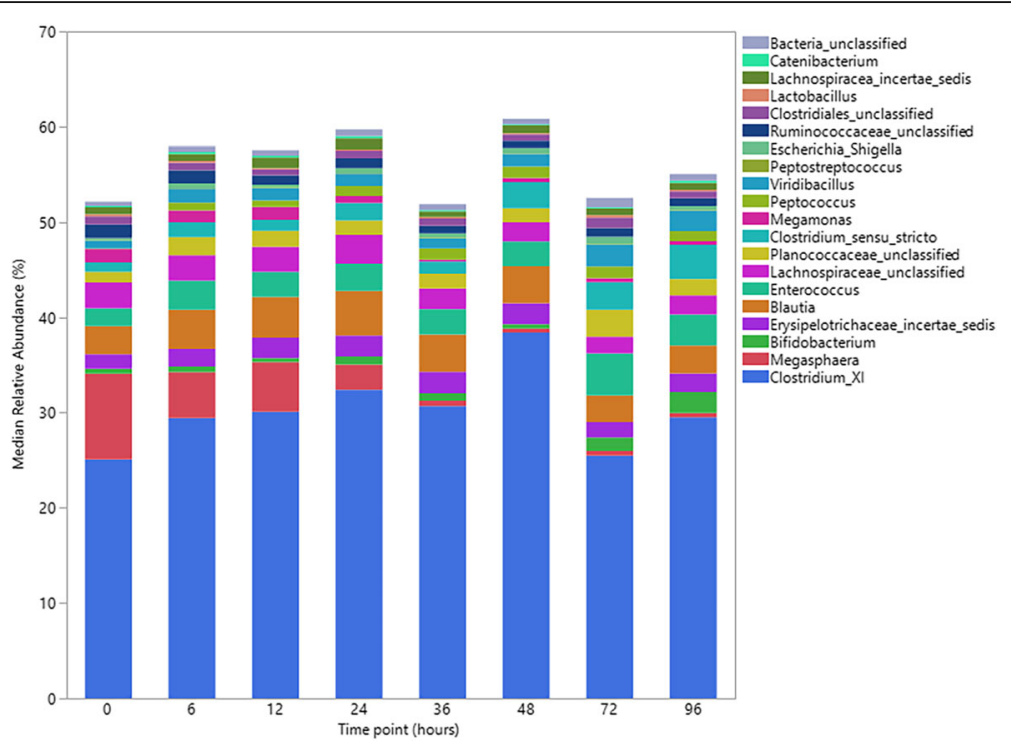

Fig. 3 Comparison of median relative abundances of predominant genera originating from fecal samples of 12 healthy cats, between time points $0,6,12,24,36,48,72$ and $96 \mathrm{~h}$ 


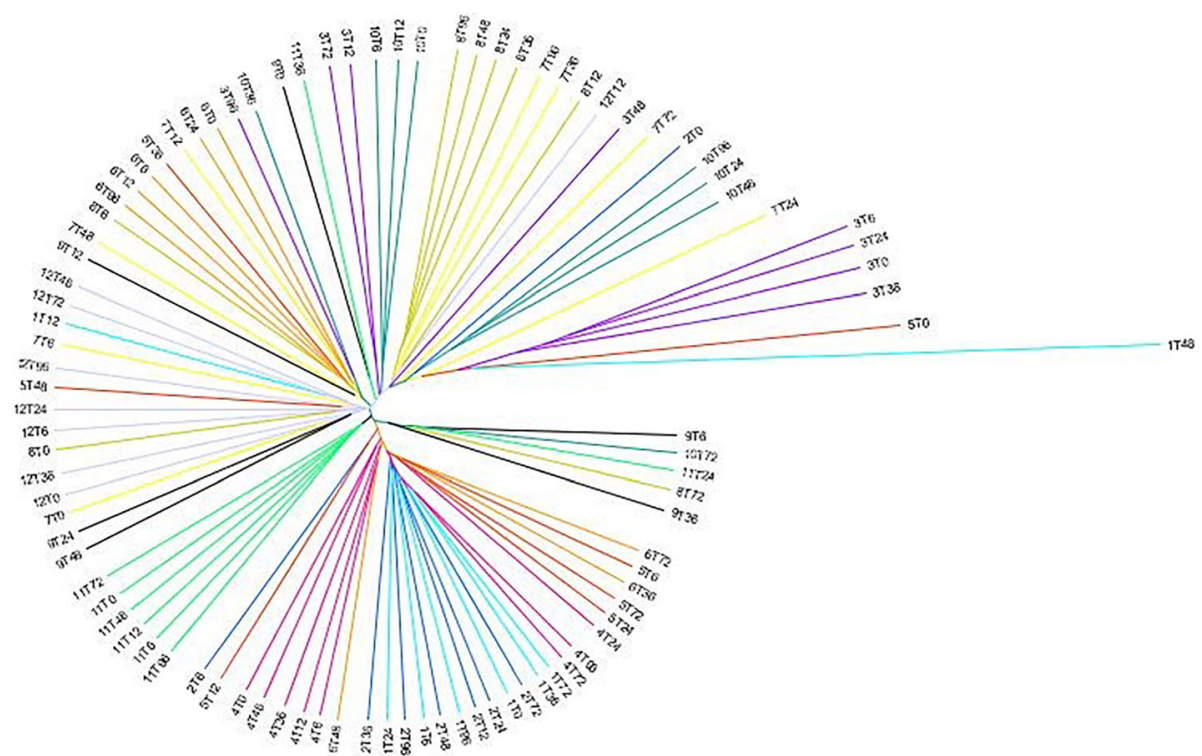

Fig. 4 Dendrogram of the Classical Jaccard index representing the community membership of the fecal microbiota in 12 healthy cats, compared between time points $0,6,12,24,36,48,72$ and $96 \mathrm{~h}$. Each cat is represented with a different colour

care must be taken when considering any nonsignificant results, these results should not be completely dismissed as statistical differences can be clouded by the degree of inter-sample variation and power limitations. The most readily apparent numerical difference was a decrease in the relative abundance over time of Megasphaera, a genus of relatively fastidious anaerobes [48]. Therefore, the trend for decreased Megasphaera abundance over time could correspond to air exposure during storage, something that might have been accentuated by manual homogenization during preparation of fecal samples. However, since the methods used in this study do not depend on viable microorganisms, it is unclear whether poor aerotolerance can accurately explain these results. Megasphaera was shown to play a dominant role in bacterial composition of the feline GI tract [49]. It is associated with ruminal fermentation of lactate into short-chain fatty acids (SCFA), and is especially related to butyrate formation [50]. Due to its fermentation capacity, the bacterium was shown to have beneficial effects on the GI health of some monogastric mammals [51, 52]. However, further research is required for the understanding of the underlined role of Megasphaera in the cat, an obligate carnivore [49], especially when increased protein content may promote a steep decrease in Megasphaera abundance, as well as jeopardise the GI microbiota health [53].

While the extent of studies investigating the impact of storage on feline fecal microbiota has been limited, the results of this study are similar to other studies that have shown limited or no impact of short-term storage. One study investigated the effect of storage at $4{ }^{\circ} \mathrm{C}$ on fecal
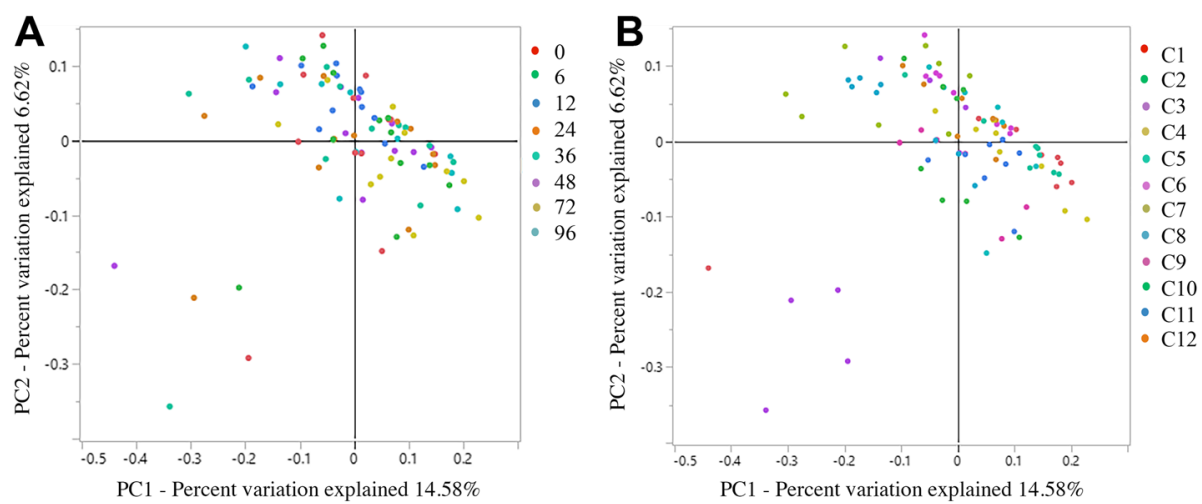

Fig. 5 Two dimensional principal coordinate analysis of population membership of the fecal microbiota of 12 healthy cats, assessed at time points 0, 6, 12, 24, 36, 48, 72 and 96 h. (a) By time point; (b) By cat 
samples from seven dogs and ten cats, after $0,3,7$ and 14 days [31]. Only a couple of significant changes were observed in the feline fecal microbiota, such as a decrease in the relative abundance of Erysipelotrichaceae incertae sedis after 7 days, or enrichment with Psychrobacter and Arthrobacter (Proteobacteria and Actinobacteria respectively) after 14 days [31]. In comparison to this refrigeration study, it would be expected that changes would occur prior to 7 days of storage at ambient temperature, which was not observed in the current study. A human study involving fecal samples from four healthy children, kept at room temperature for 12, 24, 48 and $72 \mathrm{~h}$, reported a minor change in community structure over time [29]. A small but significant increase in diversity was identified after $12 \mathrm{~h}$ along with a decrease in strains of Ruminococcus and Faecalibacterium [29]. Corresponding changes were not noted in the present study, with possible explanations being differences in sample preparation as well as inter-species variation in fecal microbiota composition. In contrast to the study by Roesch et al. (2009), non-sterile containers were used for sample preservation in the current study and fecal samples were homogenised, as performed similarly by Weese et al. (2014) $[29,31]$. Homogenization of stool assists in standardization of aliquots [4, 31, 54]. However, some researchers opt not to homogenise samples as it also causes increased oxygen exposure, which can influence the microbiota membership and structure over time [27]. Additional methodological parameters that can contribute to differences in sample membership and population structure are freeze-thaw cycles [55], differences in extraction methods [56] as well as sequencing methods. Regardless, while there have been variable results from studies in different species using different storage conditions, changes noted over the short timeframe of this study have been mild or absent, consistent with these data.

In general, changes in membership or population structure would correlate to either degradation of microbial DNA or bacterial growth. Dietary ingredients may include microbial metabolic inhibitors. Most feline diets are composed of both animal products and plants ingredients. Plant ingredients contain chlorophyll metabolites such as pheophorbide $a$ and pyropheophorbide $a$ [57], which inhibit bacterial efflux pumps [58]. The inhibitory effect of these metabolites could be one potential explanation for the lack of bacterial growth in the current study. Nonetheless, the dietary history of the cats was unavailable and further tests were not conducted to confirm this assumption.

Fecal samples in the current study were stored only for four days. This should be sufficient time in field studies to transport samples to better storage conditions, such as refrigeration or freezing. The sample size was relatively small, but it was based on a recent storage study in companion animals [31], as well as on human storage studies, that used a similar smaller sample size. Nonetheless, it is possible that with a larger sample size numerical trends in microbiota composition would become significant. Since very little research exists on the effects of storage on fecal samples in general, and even more so in cats, more research is warranted prior to solid conclusions in regards to short-term fecal storage recommendations.

\section{Conclusions}

This study demonstrate that several-day-storage of healthy cats' feces at ambient temperature, has no effect on microbial biodiversity. Although sample freezing at $-80{ }^{\circ} \mathrm{C}$ is recommended for long term storage, the current study suggests that short term storage, up to 4 days, at ambient temperatures can be appropriate, especially when field studies are performed.

\section{Endnotes}

${ }^{1}$ Denver MAXX, Denver Instrument, Bohemia, New York, USA

${ }^{2}$ Class II, Type A2 Biosafety 283 Cabinet, Thermo Fischer Scientific, Waltham, Massachusetts, USA

${ }^{3}$ E.Z.N.A. Stool DNA Kit, 284 Omega Bio-Tek Inc., Doraville, Georgia, USA

${ }^{4}$ NanoDrop 1000 Spectrophotometer, Nano 285 Drop Technologies Inc. (Thermo Fisher Scientific), Waltham, Massachusetts, USA

${ }^{5}$ Illumina, San Diego, California, USA

${ }^{6}$ Kapa Biosystems, Wilmington, Massachusetts, USA

${ }^{7}$ Mastercycler Pro, Eppendorf Canada Ltd., Mississauga, Ontario, Canada;

${ }^{8}$ SAS Campus Drive, Cary, North Carolina, USA

\section{Acknowledgements}

We wish to thank Amanda Santarossa for assisting with sample collection, Joyce Rousseau for her technical assistance with the laboratory work and Dr. Alex zur Linden for assistance with electronic artwork.

\section{Funding}

The research was supported by a Natural Sciences Engineering Research Council of Canada, Discovery Grant.

\section{Availability of data and materials}

The dataset generated and/or analysed during the current project is available at the Scholars Portal Dataverse server (https:// dataverse.scholarsportal.info/dataverse/fecal_storage_study; Data set "Replication Data for Sequences", doi:10.5683/SP/GFZHBZ)

\section{Authors' contributions}

MT, JSW and AV designed the study. MT coordinated fecal collection, and CC collected the samples. MT and CC were responsible for fecal samples extraction and analyses. MT, JSW and DEG performed bioinformatics and statistical analyses. MT drafted the manuscript. All authors contributed to manuscript preparation and approved the final manuscript. 


\section{Authors' information}

The study is within the scope of the graduate studies, Doctor Veterinary Science (DVSC) degree, of MT, who received a DVSC scholarship from the Ontario Veterinary College, University of Guelph.

\section{Ethics approval and consent to participate}

Not applicable

\section{Consent for publication}

Not applicable

\section{Competing interests}

All authors declare no conflict of interest. A.V. is the Royal Canin Veterinary Diets Endowed Chair in Canine and Feline Clinical Nutrition at the Ontario Veterinary College.

\section{Publisher's Note}

Springer Nature remains neutral with regard to jurisdictional claims in published maps and institutional affiliations.

\section{Author details}

'Department of Clinical Studies, Ontario Veterinary College, University of Guelph, Guelph, ON N1G 2W1, Canada. ${ }^{2}$ Department of Pathobiology, Ontario Veterinary College, University of Guelph, Guelph, ON N1G 2W1, Canada. ${ }^{3}$ College of Veterinary Medicine, University of Florida, Gainesville, Florida, USA.

\section{Received: 1 March 2017 Accepted: 10 August 2017}

\section{Published online: 18 August 2017}

\section{References}

1. Whitman WB, Coleman DC, Wiebe WJ. Prokaryotes: the unseen majority. Proc Natl Acad Sci U S A. 1998;95(12):6578-83.

2. Ley RE, Turnbaugh PJ, Klein S, Gordon JI. Microbial ecology: human gut microbes associated with obesity. Nature. 2006;444(7122):1022-3.

3. Manson JM, Rauch M, Gilmore MS. The commensal microbiology of the gastrointestinal tract. Adv Exp Med Biol. 2008;635:15-28.

4. Carroll IM, Ringel-Kulka T, Siddle JP, Klaenhammer TR, Ringel Y. Characterization of the Fecal Microbiota Using High-Throughput Sequencing Reveals a Stable Microbial Community during Storage. PLoS One. 2012;7(10):e46953.

5. Minamoto Y, Hooda S, Swanson KS, Suchodolski JS. Feline gastrointestinal microbiota. Anim Health Res Rev. 2012;13(1):64-77.

6. Swanson KS, Dowd SE, Suchodolski JS, Middelbos IS, Vester BM, Barry KA, Nelson KE, Torralba M, Henrissat B, Coutinho PM, et al. Phylogenetic and gene-centric metagenomics of the canine intestinal microbiome reveals similarities with humans and mice. ISME J. 2011;5(4):639-49.

7. Wagner RD. Effects of microbiota on GI health: Gnotobiotic research. In: Huffnagle GB, Noverr MC, editors. GI microbiota and regulation of the immune system. New York: Springer New York; 2008. p. 41-56.

8. McBain AJ, Macfarlane GT. Ecological and physiological studies on large intestinal bacteria in relation to production of hydrolytic and reductive enzymes involved in formation of genotoxic metabolites. J Med Microbiol. 1998:47(5):407-16.

9. Macfarlane S, Steed H, Macfarlane GT. Intestinal bacteria and inflammatory bowel disease. Crit Rev Clin Lab Sci. 2009;46(1):25-54.

10. Dore J, Corthier G. The human intestinal microbiota. Gastroenterol Clin Biol. 2010;34:S7-S15.

11. Elson CO, Sartor RB, Tennyson GS, Riddell RH. Experimental models of inflammatory bowel disease. Gastroenterology. 1995;109(4):1344-67.

12. Palm NW, De zoete MR, Cullen TW, Barry NA, Stefanowski J, Hao L, Degnan PH, Hu J, Peter I, Zhang W, et al. Immunoglobulin A coating identifies Colitogenic bacteria in inflammatory bowel disease. Cell. 2014;158(5):1000-10.

13. Gevers D, Kugathasan S, Denson LA, Vázquez-Baeza Y, Van Treuren W, Ren B, Schwager E, Knights D, Song SJ, Yassour M, et al. The treatment- naive microbiome in new- onset Crohn's disease. Cell Host Microbe. 2014;15(3):382-92.

14. Allenspach K, House A, Smith K, McNeill FM, Hendricks A, Elson-Riggins J, Riddle A, Steiner JM, Werling D, Garden OA, et al. Evaluation of mucosal bacteria and histopathology, clinical disease activity and expression of tolllike receptors in German shepherd dogs with chronic enteropathies. Vet Microbiol. 2010;146(3):326-35.
15. Pathmakanthan S. Mucosally associated bacterial flora of the human colon: quantitative and species specific differences between normal and inflamed colonic biopsies. Microb Ecol Health Dis. 1999;11(3):169-74.

16. Matsuda H, Fujiyama Y, Andoh A, Ushijima T, Kajinami T, Bamba T. Characterization of antibody responses against rectal mucosa- associated bacterial flora in patients with ulcerative colitis. J Gastroenterol Hepatol. 2000;15(1):61-8.

17. Inness VL, McCartney AL, Khoo C, Gross KL, Gibson GR. Molecular characterisation of the gut microflora of healthy and inflammatory bowel disease cats using fluorescence in situ hybridisation with special reference to Desulfovibrio spp. J Anim Physiol Anim Nutr. 2007;91(1-2):48-53.

18. Suchodolski JS, Markel ME, Garcia-Mazcorro JF, Unterer S, Heilmann RM, Dowd SE, Kachroo P, Ivanov I, Minamoto Y, Dillman EM, et al. The fecal microbiome in dogs with acute diarrhea and idiopathic inflammatory bowel disease. PLoS One. 2012;7(12):e51907.

19. Minamoto Y, Otoni CC, Steelman SM, Büyükleblebici O, Steiner JM, Jergens AE, Suchodolski JS. Alteration of the fecal microbiota and serum metabolite profiles in dogs with idiopathic inflammatory bowel disease. Gut Microbes. 2015;6(1):33-47.

20. Caricilli AM, Picardi PK, de Abreu LL, Ueno M, Prada PO, Ropelle ER, Hirabara SM, Castoldi Â, Vieira P, Camara NOS, et al. Gut microbiota is a key modulator of insulin resistance in TLR 2 knockout mice (TLR2, gut microbiota, and insulin resistance). PLoS Biol. 2011;9(12):e1001212.

21. Bisgaard H, Li N, Bonnelykke K, Chawes BLK, Skov T, Paludan-Müller G, Stokholm J, Smith B, Krogfelt KA. Reduced diversity of the intestinal microbiota during infancy is associated with increased risk of allergic disease at school age. J Allergy Clin Immunol. 2011;128(3):646-52.

22. van Nimwegen FA, Penders J, Stobberingh EE, Postma DS, Koppelman GH, Kerkhof M, Reijmerink NE, Dompeling E, van Den Brandt PA, Ferreira I, et al. Mode and place of delivery, gastrointestinal microbiota, and their influence on asthma and atopy. J Allergy Clin Immunol. 2011;128(5):948-55.

23. Johnston KL, Swift NC, Forster-van Hijfte M, Rutgers HC, Lamport A, Ballèvre $\mathrm{O}$, Batt RM. Comparison of the bacterial flora of the duodenum in healthy cats and cats with signs of gastrointestinal tract disease. J Am Vet Med Assoc. 2001;218(1):48.

24. Goodman AL, Kallstrom G, Faith JJ, Reyes A, Moore A, Dantas G, Gordon Jl. Extensive personal human gut microbiota culture collections characterized and manipulated in gnotobiotic mice. Proc Natl Acad Sci U S A. 2011; 108(15):6252-7.

25. Liu L, Li Y, Li S, Hu N, He Y, Pong R, Lin D, Lu LH, Law M. Comparison of Next- Generation Sequencing Systems. J Biomed Biotechnol. 2012. doi:10. 1155/2012/251364.

26. Mathay C, Hamot G, Henry E, Georges L, Bellora C, Lebrun L, de Witt B, Ammerlaan W, Buschart A, Wilmes P, et al. Method optimization for fecal sample collection and fecal DNA extraction. Biopreserv Biobank. 2015:13(2): 79-93.

27. Tedjo DI, Jonkers DMAE, Savelkoul PH, Masclee AA, van Best N, Pierik MJ Penders J. The effect of sampling and storage on the fecal microbiota composition in healthy and diseased subjects. PLoS One. 2015:10(5):e0126685.

28. Lauber CL, Zhou N, Gordon Jl, Knight R, Fierer N. Effect of storage conditions on the assessment of bacterial community structure in soil and human- associated samples. FEMS Microbiol Lett. 2010;307(1):80-6.

29. Roesch LFW, Casella G, Simell O, Krischer J, Wasserfall CH, Schatz D, Atkinson MA, Neu J, Triplett EW. Influence of fecal sample storage on bacterial community diversity. Open Microbiol J. 2009:3:40-6.

30. Cardona S, Eck A, Cassellas M, Gallart M, Alastrue C, Dore J, Azpiroz F, Roca J, Guarner F, Manichanh C. Storage conditions of intestinal microbiota matter in metagenomic analysis. BMC Microbiol. 2012;12(1):158.

31. Weese JS, Jalali M. Evaluation of the impact of refrigeration on next generation sequencing-based assessment of the canine and feline fecal microbiota. BMC Vet Res. 2014;10:230

32. Sturgeon A. Analysis of the Oral and Fecal Microbiota of Companion Animals Using Next-Generation Sequencing of the $16 \mathrm{~S}$ rRNA Gene. MSc Thesis. Edited by Weese JS; 2014.

33. Schloss PD, Westcott SL, Ryabin T, Hall JR, Hartmann M, Hollister EB, Lesniewski RA, Oakley BB, Parks DH, Robinson CJ, et al. Introducing mothur: open-source, platform-independent, community-supported software for describing and comparing microbial communities. Appl Environ Microbiol. 2009;75(23):7537-41.

34. Kozich JJ, Westcott SL, Baxter NT, Highlander SK, Schloss PD. Development of a dual- index sequencing strategy and Curation pipeline for analyzing 
amplicon sequence data on the MiSeq Illumina sequencing platform. Appl Environ Microbiol. 2013;79(17):5112.

35. Quast C, Pruesse E, Yilmaz P, Gerken J, Schweer T, Yarza P, Peplies J, Glockner FO. The SILVA ribosomal RNA gene database project: improved data processing and web-based tools. Nucleic Acids Res. 2013;41(D1):D590-6.

36. Edgar RC, Haas BJ, Clemente JC, Quince C, Knight R. UCHIME improves sensitivity and speed of chimera detection. Bioinformatics. 2011;27(16):2194-200.

37. Cole JR, Wang Q, Fish JA, Chai BL, McGarrell DM, Sun YN, Brown CT, PorrasAlfaro A, Kuske CR, Tiedje JM. Ribosomal database project: data and tools for high throughput rRNA analysis. Nucleic Acids Res. 2014;42(D1):D633-42.

38. Gihring T, Green S, Schadt CW. Massively parallel rRNA gene sequencing exacerbates the potential for biased community diversity comparisons due to variable library sizes. Environ Microbiol. 2011;14(2):285-90.

39. Shannon CE. A mathematical theory of communication. Bell Syst Tech J. 1948:27(3):379-423.

40. Simpson E. Measurement of Diversity. Nature. 1949;163:688.

41. Chao A. Nonparametric estimation of the number of classes in a population. Scand J Stat. 1984;11(4):265-70.

42. Benjamini Y, Hochberg $\mathrm{Y}$. Controlling the false discovery rate: a practical and powerful approach to multiple testing. J R Stat Soc Ser B Methodol. 1995;57(1):289-300.

43. Smith E. Nonparametric estimation of species richness. Biometrics. 1984; 40(1):119-29.

44. Yue J, Clayton M. A similarity measure based on species proportions. Commun Stat Theory Methods. 2005;34(11):2123-31.

45. Lozupone C, Hamady M, Knight R. UniFrac - an online tool for comparing microbial community diversity in a phylogenetic context. BMC Bioinform. 2006;7:371.

46. Segata N, Izard J, Waldron L, Gevers D, Miropolsky L, Garrett WS, Huttenhower C. Metagenomic biomarker discovery and explanation. Genome Biol. 2011;12(6):R60

47. Weese JS, Nichols J, Jalali M, Litster A. The rectal microbiota of cats infected with feline immunodeficiency virus infection and uninfected controls. Vet Microbiol. 2015;180(1-2):96-102.

48. Fernandez VM, Rao KK, Fernandez MA, Cammack R. Activation and deactivation of the membrane-bound hydrogenase from Desulfovibrio Desulfuricans. Norway strain Biochimie. 1986;68(1):43-8.

49. Deusch O, Flynn C, Colyer A, Morris P, Allaway D, Jones PG, Swanson KS. Deep Illumina-based shotgun sequencing reveals dietary effects on the structure and function of the fecal microbiome of growing kittens. PLoS One. 2014;9(7):e101021.

50. Counotte GH, Prins RA, Janssen RH, Debie MJ. Role of Megasphaera elsdenii in the fermentation of dl-2-Clactate in the rumen of dairy cattle. Appl Environ Microbiol. 1981;42(4):649.

51. Yoshida Y, Tsukahara T, Ushida K. Oral administration of lactobacillus plantarum Lq80 and Megasphaera elsdenii iNP- 001 induces efficient recovery from mucosal atrophy in the small and the large intestines of weaning piglets. Anim Sci J. 2009;80(6):709-15.

52. Hashizume K, Tsukahara T, Yamada K, Koyama H, Ushida K. Megasphaera elsdenii JCM1772 ${ }^{\top}$ normalizes hyperlactate production in the large intestine of fructooligosaccharide- fed rats by stimulating butyrate production1. J Nutr. 2003;133(10):3187-90

53. Hooda S, Vester Boler BM, Kerr KR, Dowd SE, Swanson KS. The gut microbiome of kittens is affected by dietary protein:carbohydrate ratio and associated with blood metabolite and hormone concentrations. Br J Nutr. 2013;109(9):1637.

54. Ott SJ, Musfeldt M, Timmis KN, Hampe J, Wenderoth DF, Schreiber S. In vitro alterations of intestinal bacterial microbiota in fecal samples during storage. Diagn Microbiol Infect Dis. 2004;50(4):237-45.

55. Rossmanith P, Röder B, Frühwirth K, Vogl C, Wagner M. Mechanisms of degradation of DNA standards for calibration function during storage. Appl Microbiol Biotechnol. 2011;89(2):407.

56. Albertsen M, Karst SM, Ziegler A, Kirkegaard RH, Nielsen P. Back to basics the influence of DNA extraction and primer choice on Phylogenetic analysis of activated sludge communities. PLoS One. 2015;10(7):e0132783.

57. Ma L, Dolphin D. The metabolites of dietary chlorophylls. Phytochemistry. 1999;50(2):195-202.

58. Tegos G, Stermitz FR, Lomovskaya O, Lewis K. Multidrug pump inhibitors uncover remarkable activity of plant antimicrobials. Antimicrob Agents Chemother. 2002;46(10):3133.

\section{Submit your next manuscript to BioMed Central and we will help you at every step:}

- We accept pre-submission inquiries

- Our selector tool helps you to find the most relevant journal

- We provide round the clock customer support

- Convenient online submission

- Thorough peer review

- Inclusion in PubMed and all major indexing services

- Maximum visibility for your research

Submit your manuscript at www.biomedcentral.com/submit 